\title{
The Impact of Knowledge Management on the Performance of Government Institutions Case Study of the Municipality of Bechar 'Algeria'
}

\author{
Ilyes Slimani \\ Medjdoub Bahoussi \\ Lakhdar Douli \\ Laboratory of Study Economics \& \\ Development Local in South west of Algeria \\ Department of Management \\ University of Bechar, Algeria \\ BP 49 HAI Merah Bechar, Algeria 08008
}

\begin{abstract}
This study aims to highlight the impact of knowledge management on the performance of government institutions at the level of the municipality of Bechar 'Algeria', which represents a study population enterprise workers was selected a sample of them, but the completion of this study has been prepared consisting of a three-part questionnaire devoted the first part of personal information, and part the second respect to knowledge management, and the third part regards the performance, has been tested this effect, where the results of the study indicated that the impact of knowledge management and dimensions of knowledge management on organizational loyalty when the municipality of Bechar 'Algeria' high institution workers, and there are significant differences between the independent variables differences the dimensions of knowledge management with the dependent variable the performance.
\end{abstract}

Keywords: Knowledge Management, The Performance, Government Institutions, Municipality of Bechar

\section{Introduction}

The Department has undergone several fundamental transformations within the concepts of government sector management, with the shift to leadership, the supremacy of service recipients, performance management, service improvement and accountability for results. In order to improve government performance and effectiveness, but all agreed on the need to develop government management in line with the nature of the goals and aspirations of modern societies through the inclusion of the concept of knowledge management and how to employ to provide better, and thus raise the level of public service performance, and eliminate the manifestations of routine and weakness and slow performance, And mismanagement of public resources of the State.

Performance depends on the human dimension. Man is the main element of the growth and development of organizations, especially in the cognitive aspect, which is the most valuable capital for all organizations.

\section{1- Problematic study}

What is the impact of knowledge management on the performance of government institutions?

\section{2- The Hypotheses of the study}

$>$ Hypothesis 1:

$\mathbf{H}_{\mathbf{0}}$ : There is no significant effect of knowledge management dimensions (knowledge management processes, knowledge management technology, and knowledge team) on internal processes of performance at a significant level of $5 \%$.

$\mathbf{H}_{1}$ : There is a significant effect of knowledge management dimensions (knowledge management processes, knowledge management technology, and knowledge team) on the internal processes of performance at a significant level of $5 \%$.

$>$ Hypothesis 2:

H0: There is no significant effect on knowledge management dimensions (knowledge management processes, knowledge management technology, knowledge team) on learning and growth at a significant level of 5\%.

H1: There is a significant effect of knowledge management dimensions (knowledge management processes, knowledge management technology, and knowledge team) on learning and growth at a significant level of 5\%.

$>$ Hypothesis 3: 
H0: There is no significant effect of knowledge management dimensions (knowledge management processes, knowledge management technology, and knowledge team) on citizens at a significant level of 5\%.

H1: There is a significant effect on the dimensions of knowledge management (knowledge management processes, knowledge management technology, and knowledge team) on citizens at a significant level of 5\%.

$>$ Hypothesis 4:

H0: There is no significant effect of knowledge management dimensions (knowledge management processes, knowledge management technology, and knowledge management team) on performance at a significant level of $5 \%$.

H1: There is a significant effect of knowledge management dimensions (knowledge management processes, knowledge management technology, and knowledge management team) on performance at a significant level of 5\%.

$>$ Hypothesis 5:

H0: There is no significant effect of knowledge management on performance at a significant level of 5\%.

H1: There is a significant effect of knowledge management on performance at a significant level of 5\%.

\section{The Theory Study}

\section{1- Knowledge Management}

Knowledge management is defined as a „process used by organizations for generating new value from intellectual sources or knowledge-based sources". Very often this knowledge management process includes sharing newly created knowledge among employees, departments, even among companies. It needs to be noted that this definition does not mention anything about information technologies. It often happens that in some analyses knowledge management is integrated with information technology, but that not what knowledge management is about.(Neven Bosilj, 2009)

A review of the processes identified as knowledge management processes by various authors allows us to distinguish four key knowledge management processes: (Martelo-Landroguez, 2016)

1) Knowledge creation,

2) knowledge transfer,

3) knowledge storage/retrieval,

4) knowledge application.

In order to assess the importance of each knowledge management process in knowledge management, key knowledge management processes as formative components of knowledge management (see Figure): (Martelo-Landroguez, 2016)

Figure 1 : The knowledge management process

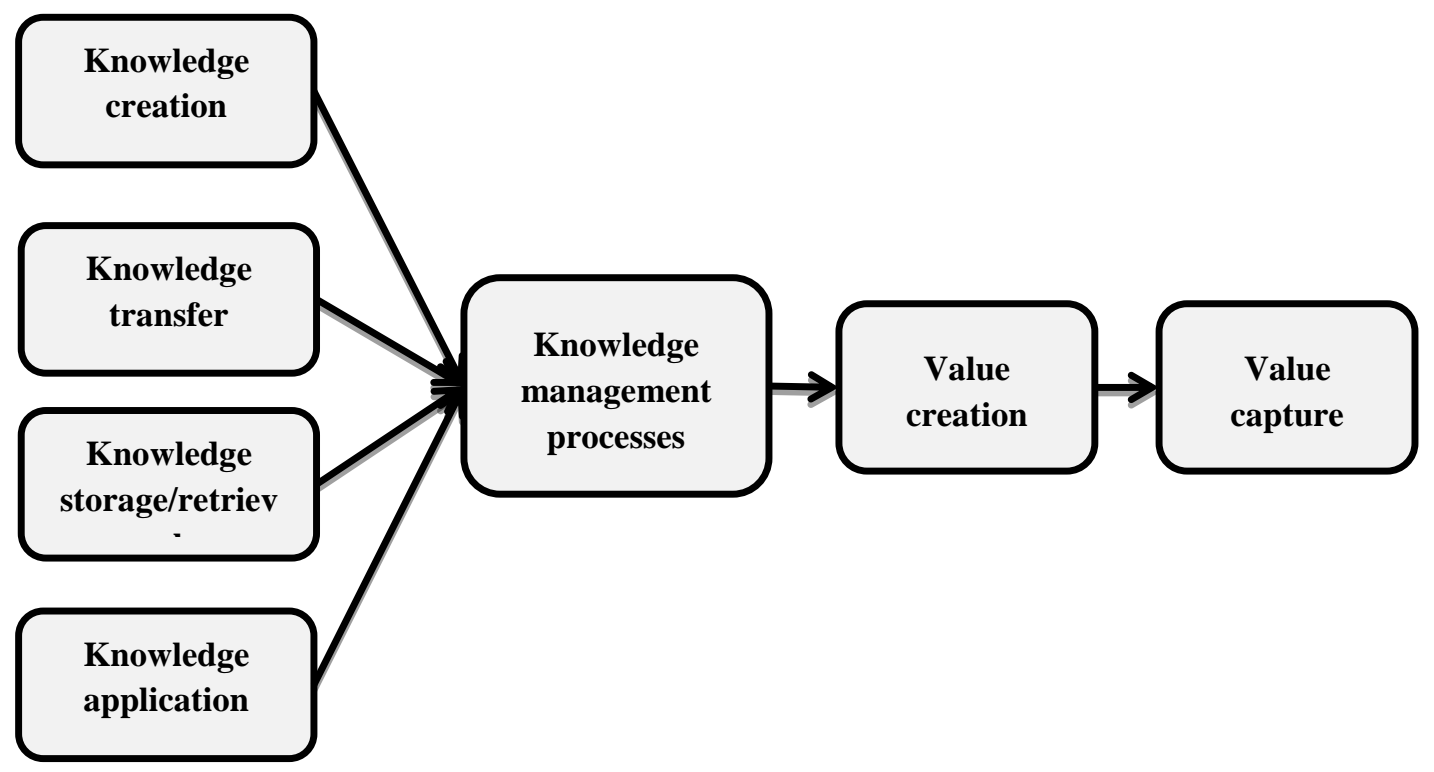

\section{2- The Performance}

Without giving an universal definition of performance, we present below the three accepted approaches of performance mentioned (Mirela-Oana Pintea, 2010): 
$>$ Performance is action. In this sense, performance is a process and not a result that appears at a time. Performance is not a state but a process and its content became almost secondary in relation to its own dynamics.

$>$ Performance is the result of the action. Performance measurement is understood as "ex post assessment the results".

$>$ Performance means success. Performance does not exist by itself, is in fact a dependent representation of the success of the different categories of users of accounting information.

According to some authors (Mirela-Oana Pintea, 2010) performance is "a particular result obtained in management, economics, marketing, etc.. that print features of competitiveness, efficiency and effectiveness of the organization and its procedural and structural components. Performance canberegarded as the equivalent of competitiveness.

\section{3- The Performance of Government Institutions}

Local government performance can be explained and evaluated from several perspectives. The first line of thinking emphasizes citizen engagement and participation. Proponents of citizenry engagement and participation theory argue that without involvement and participation of local communities in governance affairs, public institutions like the municipalities, for example, are less likely to improve their performance in terms of provision of public goods and services as well as managing public funds. While community engagement and participation is emphasized in democratic contexts for promoting institutional performance, in African contexts of hybrid democracies it can contribute to ensuring accountability in the use of public resources by government institutions and the consolidation of democracy at the local level.(MAMOGALE, December 2014)

Figure 2: Interpretation of the concept of performance of government institutions

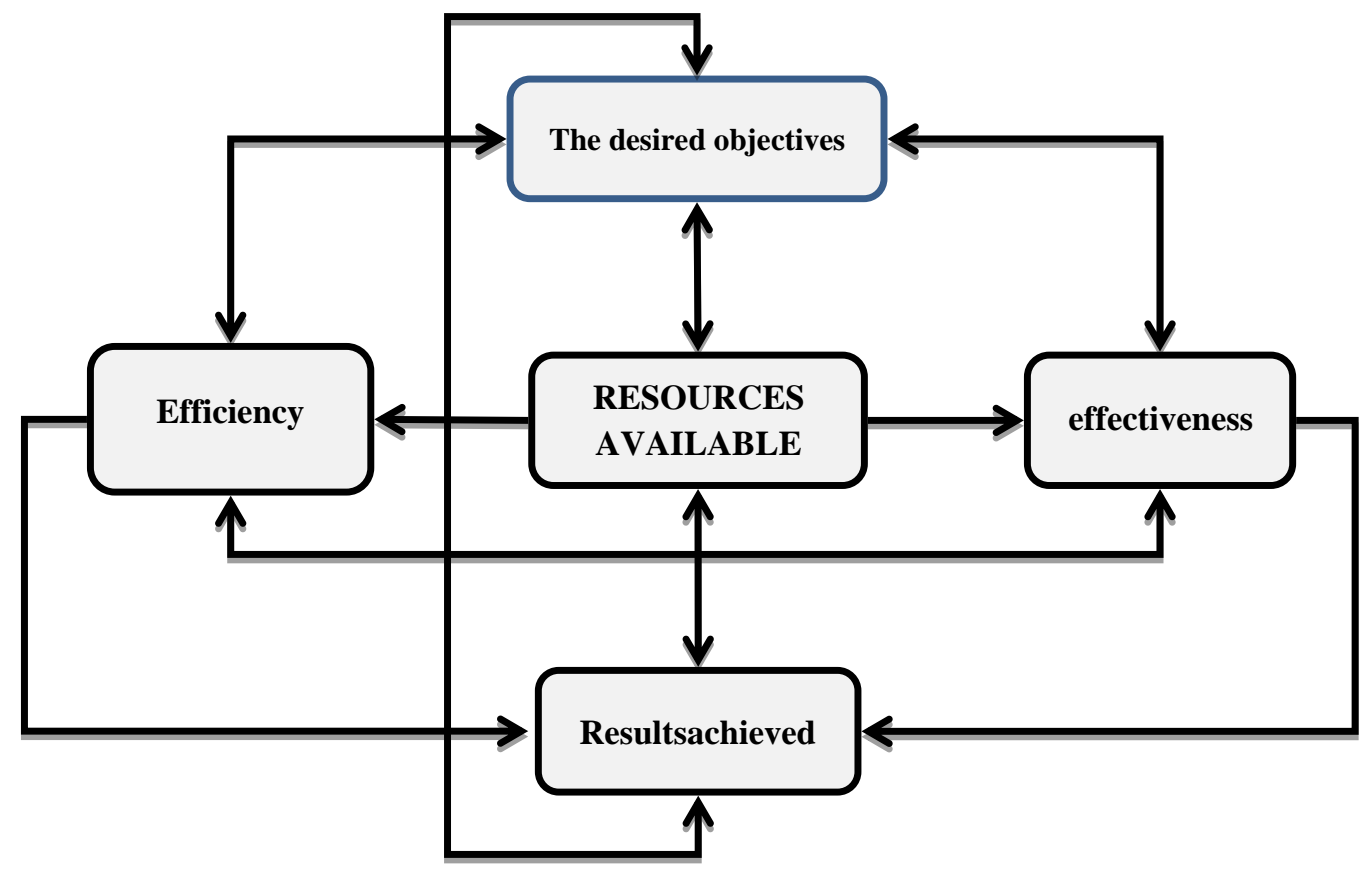

\section{The Field Study}

\section{1- The Definition of the institution a study spot (Municipality of Bechar)}

The municipality is a public (non-private) community, concerned with the inhabitants of the area where the municipality has its headquarters, which grants the residents of this area autonomy from the central administrative authority in the capital or region. It has a specific land area and enjoys a civil personality. It has a name, a date of birth or a date of creation, and has multiple tasks.

\section{2- The Origin and Development of Bechar Municipality}

It was the first administrative organization of the municipality of Bechar in 1905. It joined a military district of Ain alsafra and was transformed into a mixed municipality. In 1957, it was divided into two municipalities (Bechar al-Wasat and Dabdaba). In 1958, Decree No. 63-189 of May 16, 1963 establishing the municipality of Bashar. The municipal people's councils were established on 18/01/1967. In 1971, the municipality of Taghit was independent. In 1985, the municipalities of Lahmer and Moghl became autonomous. 
The municipality has adminestatives annexes that contribute to bringing the administration closer to the citizen and taking into account its affairs. A special delegate is appointed from among the members of the Municipal People's Assembly and acts under the responsibility of the Speaker of the People's Assembly.

The annexes of the municipality of Bechar as follows:

$>$ Debedaba

$>$ BecharEldjadid

$>$ Wakda

$>$ Hai El Badr

$>$ HaiEldjourf

$>$ HaiElmongar

$>$ HaiMerah

$>$ Bechar Al-Wasat.

The Municipality has contributed to improving the public service through several measures:

$>$ Reducing the number of administrative documents of the civil situation.

$>$ Revoke authentication on replicas.

$>$ To exempt citizens from submitting civil status documents available in the electronic register.

\section{3- The study population and type of Sample:}

The study population consists of all the employees of Bechar municipality, without regard their job position, The number of employees was 896. The sample of the study was used. We used the equation of Richard Geiger, and we obtained a sample of 270 .

Figure 2: The Study Variables

\section{INDEPENDENT VARIABLE}

THE DEPENDENT VARIABLE

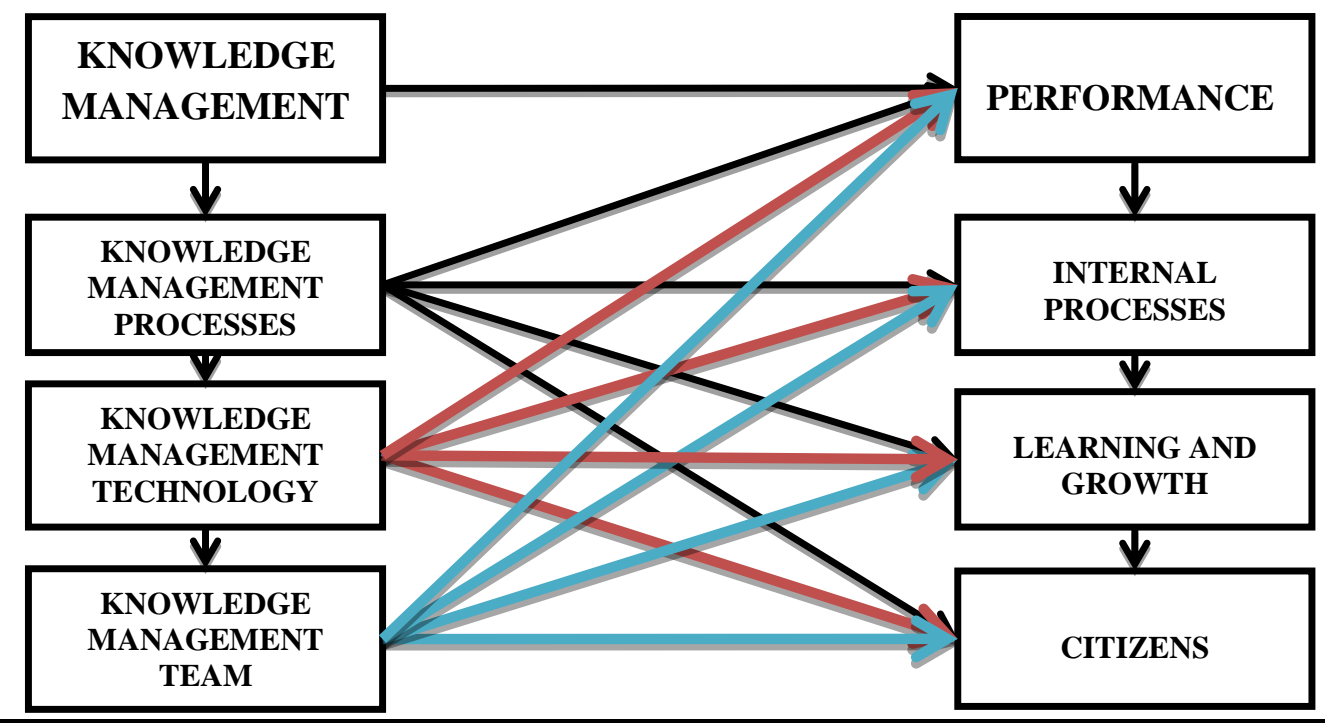

4- Analyzing the results of the questionnaire

We used to divide the Likert where it meets every question from the axis of the questionnaire five options divided into grades as follows:

\begin{tabular}{|c|c|c|c|c|}
\hline Very Dissatisfied & $\begin{array}{c}\text { Somewhat } \\
\text { Dissatisfied }\end{array}$ & Neutral & $\begin{array}{c}\text { Somewhat } \\
\text { Satisfied }\end{array}$ & Very Satisfied \\
\hline $1-1.79$ & $\mathbf{1 . 8 0 - 2 . 5 9}$ & $\mathbf{2 . 6 0 - 3 . 3 9}$ & $\mathbf{3 . 4 0 - 4 . 1 9}$ & $\mathbf{4 . 2 0 - 5}$ \\
\hline
\end{tabular}

$>$ Results of the study data analysis and hypothesis testing Data Analysis Reliability

Table 2: Reliability

\begin{tabular}{|c|c|}
\hline \multicolumn{2}{|c|}{ Statistiques de fiabilité } \\
\hline Alpha de Cronbach & Nombre d'éléments \\
\hline 0.721 & 58 \\
\hline
\end{tabular}


Note from Table (2) alpha coefficient greater than the minimum acceptable and is $60 \%$ to overall reliability coefficient $72.1 \%$, indicating a high reliability

$>$ Hypothesis Testing

Table 3:The results of path estimation between the dimensions of knowledge management and internal processes of performance

\begin{tabular}{|c|c|c|c|c|c|}
\hline & Estimate & S.E & C.R & $P$ & Result \\
\hline KMPIINAEENAL PROCESSES & 0.174 & 0.071 & 2.459 & 0.014 & Accepted \\
\hline KMT $^{2}$ NAERNASPROCESSES & 0.204 & $\mathbf{0 . 0 3 8}$ & 5.310 & $* * *$ & Accepted \\
\hline KMT $^{3}$ ANFANALPOCESSES & 0.178 & 0.048 & 3.733 & $* * *$ & Accepted \\
\hline
\end{tabular}

Source: The preparation of researcher and the adoption of the Amos ${ }_{\mathrm{v} 22}$.

Analysis:The results of the table show that the values of level (p), which represent the degree of morale for all the dimensions of knowledge management, are less than the measured level of significance $(\alpha=0.05)$ and $(\boldsymbol{p}<\boldsymbol{\alpha})$. Since the values of the critical ration (C.R) for all dimensions of knowledge management is larger than the value of 1.96, which represents the significant degree of natural distribution at a significant level of 0.05 (CR> 1.96).

Table 4:The results of path estimation between the dimensions of knowledge management, learning and growth

\begin{tabular}{|l|c|c|c|c|c|}
\hline & Estimate & S.E & C.R & $P$ & Result \\
\hline KMPLEARNA AND GROWTH & 0.099 & 0.114 & $\mathbf{0 . 8 7 0}$ & $\mathbf{0 . 3 8 4}$ & Rejected \\
\hline $\begin{array}{l}\text { KMT LEARNING AND } \\
\text { GROWTH }\end{array}$ & 0.148 & $\mathbf{0 . 0 6 2}$ & 2.394 & $\mathbf{0 . 0 1 7}$ & Accepted \\
\hline $\begin{array}{l}\text { KMT LEARNING AND } \\
\text { GROWTH }\end{array}$ & 0,182 & 0.077 & 2.367 & $\mathbf{0 . 0 1 8}$ & Accepted \\
\hline
\end{tabular}

Source: The preparation of researcher and the adoption of the Amos ${ }_{\mathrm{v} 22}$.

Analysis:The results of the table show that the values of level (p), which represent the degree of morale for all dimensions of knowledge management, were less than the calculated level of significance $(\alpha=0.05)$ and $(\boldsymbol{p}<\boldsymbol{\alpha})$ for both knowledge management technology and knowledge management team. Knowledge Management $(\mathrm{P}>\alpha)$ Since the $\mathrm{CR}$ values for both KM and Knowledge Management teams are greater than 1.96, which is the normal score of normal distribution at 0.05 (CR) 1.96, The knowledge management processes were less than 1.96 (CR <1.96).

Table 5:The results of path estimation between the dimensions of knowledge management and citizens

\begin{tabular}{|c|c|c|c|c|c|}
\hline & Estimate & S.E & C.R & $P$ & Result \\
\hline KMPCITHENS $\longrightarrow$ & 0.199 & 0.097 & 2.063 & 0.039 & Accepted \\
\hline KMT $\longrightarrow$ CITIZENS & 0.072 & $\mathbf{0 . 0 5 3}$ & 1.375 & 0.169 & Rejected \\
\hline CITIZENS & 0,107 & $\mathbf{0 , 0 6 5}$ & -1.640 & 0.101 & Rejected \\
\hline
\end{tabular}

Source: The preparation of researcher and the adoption of the Amos $\mathrm{v22}$.

Analysis: From the results of the table we find that the values of the level (p), which represent the degree of morale for all the dimensions of knowledge management, were less than the calculated level of significance $\alpha=0.05(p<\alpha)$ for the variable knowledge management processes, while $(\mathrm{p}>\alpha)$ For the variables Knowledge Management Technology and Knowledge Management Team. Critical Criterion (CR) values for both Knowledge Management Technology and KMT are less than 1.96, which is the normal score of normal distribution at 0.05 (CR <1.96) ), And the critical ratio of knowledge management operations was greater than 1.96 (CR>1.96).

\footnotetext{
${ }^{1}$ KNOWLEDGE MANAGEMENT PROCESSES

${ }^{2}$ KNOWLEDGE MANAGEMENT TECHNOLOGY

${ }^{3}$ KNOWLEDGE MANAGEMENT TEAM
} 
Table 6:The results of path estimation between the dimensions of knowledge management and performance

\begin{tabular}{|c|c|c|c|c|c|}
\hline & Estimate & S.E & C.R & $P$ & Result \\
\hline KMPPERFOR & 0.159 & $\mathbf{0 . 0 5 2}$ & 3.065 & $\mathbf{0 . 0 0 2}$ & Accepted \\
\hline KMT $\longrightarrow$ PERFORMANCE & 0.158 & $\mathbf{0 . 0 2 8}$ & $\mathbf{5 . 6 0 1}$ & & Accepted \\
\hline KMTPERFORTANCE & $\mathbf{0 , 1 1 3}$ & $\mathbf{0 , 0 3 5}$ & $\mathbf{3 , 2 2 2}$ & $\mathbf{0 , 0 0 1}$ & Accepted \\
\hline
\end{tabular}

Source: The preparation of researcher and the adoption of the Amos ${ }_{\mathrm{v} 22}$.

Analysis:The results of the table show that the values of level (p), which represent the degree of morale for all the dimensions of knowledge management, are less than the measured level of significance $(\alpha=0.05)$ and $(\boldsymbol{p}<\boldsymbol{\alpha})$. The value of 1.96, which represents the significant degree of natural distribution at a significant level of 0.05 (CR>1.96).

* Test the relationship between knowledge management and performance

Table 7:The results of path estimation between the knowledge management and performance

\begin{tabular}{|c|c|c|c|c|c|}
\hline & Estimate & S.E & C.R & $P$ & Result \\
\hline ANPENORMANCE & $\mathbf{0 . 4 8 2}$ & $\mathbf{0 . 0 5 4}$ & $\mathbf{8 . 9 1 6}$ & & Accepted \\
\hline
\end{tabular}

Source: The preparation of researcher and the adoption of the Amos ${ }_{\mathrm{v} 22}$.

Analysis:The results of the table show that the value of (p), which represents the moral level of knowledge management, is less than the measured level of significance $(\alpha=0.05)$ and $(p<\alpha)$, Since the Critcal ration value for knowledge management is greater than the value of 1.96, which represents the significant degree of normal distribution at a significant level of $0.05(\mathrm{CR}>1.96)$.

\section{5- Results of the study found the following results:}

$>$ There is a significant effect between the processes of knowledge management and internal processes of performance at a significant level of $5 \%$.

$>$ There is a significant effect between the knowledge management technology and the internal processes of performance at a significant level of $5 \%$.

$>$ There is a significant effect between the knowledge team and the internal processes of performance at a significant level of $5 \%$.

$>$ There is no significant effect of knowledge management processes on learning and growth performance at a significant level of $5 \%$.

$>$ There is a significant effect of knowledge management technology on learning and growth of performance at a significant level of $5 \%$.

$>$ There is a significant effect of knowledge management team on learning and growth performance at a level of 5\%.

$>$ There is a significant effect of knowledge management processes on citizens at a significant level of 5\%.

$>$ There is no significant effect of knowledge management technology on citizens at a significant level of 5\%.

$>$ There is no significant impact of knowledge management team on citizens at a level of 5\%.

$>$ There is a significant effect of knowledge management processes on performance at a significant level of 5\%.

$>$ There is a significant effect of knowledge management technology on performance at a significant level of 5\%.

$>$ There is a significant effect of knowledge management team on performance at a significant level of 5\%.

"There is an impact of knowledge management on performance at a significant level of 5\%".

\section{6- The study recommends the following:}

$>$ Knowledge management is important because it is the essential asset that helps institutions to succeed, if that knowledge is used by individuals and can be obtained through the environment around them.

$>$ The Knowledge management is a scientific field that provides organizations with a great deal of excellence and improved performance through its various dimensions of knowledge management processes, knowledge management technology and knowledge management team.

$>$ The Knowledge management is one of the fields that are subject to rapid changes in the field of operations related to it. These processes are key to achieving optimal investment of knowledge, keeping pace with changes, achieving goals and improving performance.

$>$ The positive and effective role of knowledge management must be activated to ensure that the performance of the organization is raisedStudy. 


\section{Bibliographie}

MAMOGALE, M. J. (December 2014). Financial Performance of Local Government in Limpopo Province, 2010-2012. African Studies Quarterly, 74.

Martelo-Landroguez, S. (2016). How knowledge management processes can create and capture value for firms? https://idus.us.es/xmlui/bitstream/handle/11441/54653/how\%20knowledge\%20management\%20processes\%20 can $\% 20$ create.pdf? sequence $=1,3$.

Mirela-Oana Pintea, M.-V. A. (2010). PERFORMANCE - AN EVOLVING CONCEPT. Annals of the university of craiova economic sciences series, 3 .

Neven Bosilj, I. J. (2009). The Role of Knowledge Management in Mobile Marketing. Journal of Information and Organizational Sciences, 231. 